\title{
Understanding of Passivation Mechanism in Heterojunction c-Si Solar Cells
}

\author{
Michio Kondo ${ }^{1}$, Stefaan De Wolf ${ }^{1,2}$, and Hiroyuki Fujiwara ${ }^{1}$ \\ ${ }^{1}$ RCPV, AIST, Umezono, Tsukuba, 305-8568, Japan \\ ${ }^{2}$ Institute of Microtechnique, University of Neuchâtel, Rue Breguet 2, Neuchâtel, CH-2000, \\ Switzerland
}

Intrinsic hydrogenated amorphous silicon $(a-\mathrm{Si}: \mathrm{H})$ films can yield in outstanding electronic surface passivation of crystalline silicon $(c-\mathrm{Si})$ wafers as utilized in the HIT (heterojunction with intrinsic thin layer) solar cells. We have studied the correlation between the passivation quality and the interface nature between thin amorphous layers and an underlying c-Si substrate for understanding the passivation mechanism. We found that a thin $(\sim 5 \mathrm{~nm})$ intrinsic layer is inhomogeneous along the growth direction with the presence of a hydrogen rich layer at the interface and that completely amorphous films result in better passivation quality and device performance than an epitaxial layer. Post annealing improves carrier lifetime for the amorphous layer, whereas the annealing is detrimental for the epitaxial layer. We have also found that the passivation quality of intrinsic $a-\mathrm{Si}: \mathrm{H}(i)$ film deteriorates severely by the presence of a boron-doped $a-\mathrm{Si}: \mathrm{H}\left(p^{+}\right)$overlayer due to $\mathrm{Si}-\mathrm{H}$ rupture in the $a$ $\mathrm{Si}: \mathrm{H}(i)$ film. Finally, for a passivation layer in the hetero-junction structure, $a-\mathrm{Si}_{1-\mathrm{x}} \mathrm{O}_{\mathrm{x}}$ will be demonstrated in comparison with $a-\mathrm{Si}: \mathrm{H}$.

\section{INTRODUCTION}

Hydrogenated amorphous silicon $(a-\mathrm{Si}: \mathrm{H})$ films deposited on crystalline silicon $(c-\mathrm{Si})$ surfaces have increasingly attracted attention over the past years. Initially it was discovered that abrupt electronic heterojunctions can be created with such structure[1], followed by an application to solar cells[2]. Structures featuring a wider bandgap emitter have in the past already been suggested to allow for maximal photovoltaic device performance[3]. For $a$-Si:H / $c$-Si heterostructures, it was found that the output parameters benefit substantially from inserting a few nm thin intrinsic $a-\mathrm{Si}: \mathrm{H}(i)$ film between the doped amorphous emitter and $c$-Si substrate. Direct deposition of doped $a$-Si:H films on $c$-Si surfaces has been speculated to result in poor interface properties because of a defective property of doped $a-\mathrm{Si}: \mathrm{H}$. Presently, for solar cells that feature a heterostructure emitter and back surface field, impressive energy conversion efficiencies exceeding $22 \%$ have been reported [4]. Nevertheless, despite these results, a physical understanding of the $a-\mathrm{Si}: \mathrm{H} / c$-Si interface is not yet complete.

In this paper, we summarize our study on understanding the mechanism of the electronic passivation and the interface nature between thin amorphous layers and an underlying $c$-Si substrate. The article is organized as follows: First we discuss results obtained by real-time spectroscopic ellipsometry (SE) and attenuated total reflection (ATR) measurements. This yields insight in the growth mechanism of hydrogenated $a$-Si:H layers on $c$-Si surfaces.

In a second part, an annealing study of thin stacked doped $a$-Si:H films is presented where electronic passivation results are linked to material properties. These studies are useful for two reasons: Firstly, postdeposition annealing offers a single parameter to vary both electronic and material properties of the samples under study, from which additional physical insights may be obtained. Secondly, such treatments may be beneficial for the structures under study, and hence are also relevant from device processing point of view.

Lastly, interpretation of the deposition condition dependence of the solar cell performance is discussed in conjunction with different amorphous materials for heterojunction. 


\section{EXPERIMENTAL}

\section{Sample preparation}

For the experiments, 300-320 $\mu \mathrm{m}$ thick relatively low resistivity boron-doped ( 3.0 $\Omega . c m)$ as well as phosphorus-doped $(\sim 0.7 \Omega . c m)$ high quality float zone (100) FZ-Si wafers have been used. Both surfaces of the substrates were mirror polished to eliminate the influence of substrate surface roughness on the passivation properties [5], and to allow for SE measurements.

For pre-deposition surface cleaning, the samples were first immersed in a $\left(\mathrm{H}_{2} \mathrm{SO}_{4}: \mathrm{H}_{2} \mathrm{O}_{2}\right)$ (4:1) solution for 10 min to grow a chemical oxide, which was followed by a rinse in deionized water. The oxide was then stripped off in a dilute HF solution (5\%) for $30 \mathrm{sec}$. After this the samples were immediately transferred to the load lock of the deposition system.

For $a$-Si:H film deposition, a parallel plate direct-plasma enhanced chemical vapor deposition (PECVD) systems were used. During film deposition, all chambers were operated at radio frequency $(\mathrm{rf})(13.56 \mathrm{MHz})$ power and a pressure between 0.05 and 0.5 Torr. For soft film deposition, the power desity was consistently the minimum required to maintain stable plasmas, typically $\sim 10 \mathrm{~mW} / \mathrm{cm}^{2}$. The value for $T_{\text {depo }}$ was varied from $105^{\circ} \mathrm{C}$ to $255^{\circ} \mathrm{C}$. For intrinsic films $20 \mathrm{SCCM} \mathrm{SiH}_{4}$ was used, for boron doped films this was $10 \mathrm{SCCM}$, mixed in $30 \mathrm{SCCM} \mathrm{B}_{2} \mathrm{H}_{6}\left(4660 \mathrm{ppm}\right.$ in $\left.\mathrm{H}_{2}\right)$.

The a-Si:H/c-Si heterojunction solar cells in this study consist of $\mathrm{Ag}$ grid/ $/ \mathrm{In}_{2} \mathrm{O}_{3}: \mathrm{Sn} / \mathrm{a}-$ $\mathrm{Si}: \mathrm{H}(\mathrm{p}) / \mathrm{a}-\mathrm{Si}: \mathrm{H}(\mathrm{i}) / \mathrm{c}-\mathrm{Si}(\mathrm{n}) / \mathrm{Al}$. The solar cell efficiencies were determined from solar cells having active area of $0.21 \mathrm{~cm}^{2}$ under AM 1.5 illumination $\left(100 \mathrm{~mW} / \mathrm{cm}^{2}\right)$, and solar cell efficiencies designated in this study represent active area efficiencies.

\section{In-situ measurements}

For real-time monitoring of the film deposition processes, real-time spectroscopic ellipsometry (SE) and infrared attenuated total reflection spectroscopy (ATR) have been performed using the system shown in Fig. 1 [6-9]. During the a-Si:H p-i layer growth, ellipsometry spectra $(\psi, \Delta)$ were collected using a rotating-compensator instrument (J. A. Woollam, M-2000). The SE analysis was performed in real time using a two-layer model for the a-Si:H film consisting of ambient/surface roughness layer/bulk layer/substrate. The dielectric function of the surface roughness layer was modeled as a 50/50 vol.\% mixture of the bulk layer material and voids. We obtained the dielectric function of the a-Si:H bulk layer in advance from an a-Si:H i-layer (200 $⿱$ A) using a global error minimization scheme [8]. The a-Si:H p-layer was analyzed by applying the dielectric function of the i-layer, as we find that the dielectric function of the p-layer is rather similar to that of the i-layer when the p-layer thickness is thin $(\sim 50 \AA)$. On the other hand, the real-time ATR spectra were measured by employing a Fourier-transform infrared instrument (Nicolet, Magna 560). For the ATR measurement, we used trapezoidal non-dope c-Si substrates $(\sim 1000 \Omega \mathrm{cm})$. Thus, only the SE measurement was carried out when the a-Si:H layers were deposited on the n-type substrate to fabricate the solar cell. Details of the measurements and data analysis procedures for real-time SE $[8,9]$ and ATR $[6,9]$ have been reported elsewhere. 


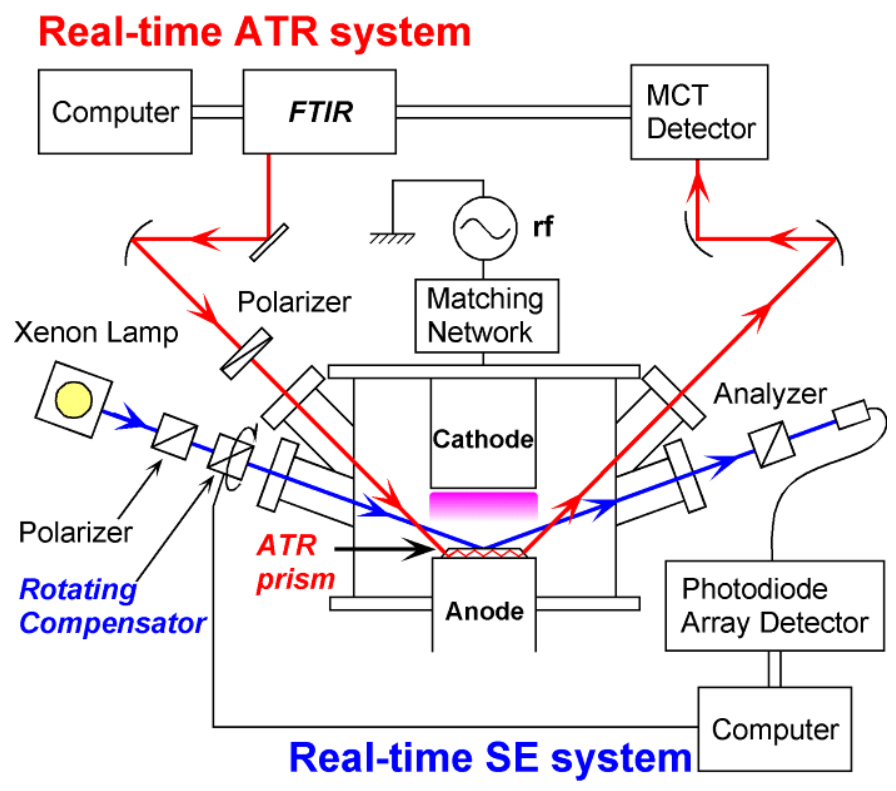

Fig. 1. Schematic of the plasma-enhanced CVD system and the real-time measurements by SE and ATR.

\section{Ex-situ measurements}

To gain knowledge about the electronic surface passivation properties of these interfaces, the most straightforward technique is to measure the effective carrier lifetime, $\tau_{\text {eff }}$, of the samples. The value for $\tau_{\text {eff }}$ of the samples was measured with a Sinton Consulting WCT-100 quasi steady state photoconductance system [10], operated in the so-called generalized mode. Since high quality FZ-Si wafers have been used throughout the experiments, the contribution of the bulk to the total recombination expressed by $\tau_{\text {eff }}$ can be neglected. In such a case, the effective surface recombination velocity, $S_{\text {eff }}$, which value can be regarded as a direct measure for the passivation quality of the films present at the surfaces, may be approximated by $S_{\text {eff }}=$ $d^{*}\left(2 \tau_{\mathrm{eff}}\right)^{-1}$, with $d$ being the wafer thickness. All reported values for $\tau_{\mathrm{eff}}$ and $S_{\text {eff }}$ are evaluated at a constant minority carrier injection density, $\Delta n$, of $1.0 \times 10^{15} \mathrm{~cm}^{-3}$. The thickness of the deposited films was ex-situ determined by measuring ellipsometry spectra $(\psi, \Delta)$ using a Woollam M-2000 rotating-compensator instrument.

We have studied the effects of low temperature (up to $260^{\circ} \mathrm{C}$ ) post-deposition annealing upon the surface passivation quality of $a-\mathrm{Si}: \mathrm{H}(i)$ films with or without a boron-doped $a-\mathrm{Si}: \mathrm{H}\left(p^{+}\right)$over-layer on top of $c-\mathrm{Si} / a-\mathrm{Si}: \mathrm{H}(i)$. The samples were consecutively annealed in a vacuum furnace (30 min, with annealing temperatures, $T_{\mathrm{ann}}$, ranging from $120^{\circ} \mathrm{C}$ to $260^{\circ} \mathrm{C}$ and a $20^{\circ} \mathrm{C}$ increment per step). 
For bulk characterization of the films, thermal desorption spectroscopy (TDS) measurements were taken. For this an ESCO EMD-WA1000S system operated at ultra high vacuum $\left(<1.0 \times 10^{-9}\right.$ Torr $)$ is used in which the samples are lamp-heated up to $1000{ }^{\circ} \mathrm{C}$, with a linear temperature ramp of $20 \mathrm{~K} \cdot \mathrm{min}^{-1}$. During the annealing, a Balzers AG QMG 421 quadrupole mass spectrometer was used to determine the $\mathrm{H}_{2}$ effusion rate from the $a-\mathrm{Si}: \mathrm{H}$ films. Throughout this article the following shorthand notations are used: $i, p^{+}$and $i / p^{+}$for respectively the $c-\mathrm{Si} / a-\mathrm{Si}: \mathrm{H}(i), c-\mathrm{Si} / a-\mathrm{Si}: \mathrm{H}\left(p^{+}\right)$and $c-\mathrm{Si} / a-\mathrm{Si}: \mathrm{H}(i) / a-\mathrm{Si}: \mathrm{H}\left(p^{+}\right)$structures.

\section{RESULTS AND DISCUSSION}

\section{Thickness dependence of the i-layer}

Figure 2 shows (a) depth profiles of hydrogen contents determined from SE-ATR results and (b) solar cell efficiency, plotted as functions of the thickness of a-Si:H i-layer deposited at $130{ }^{\circ} \mathrm{C}$. The result shown in Fig. 2(a) was obtained from the growth of a thick a$\mathrm{Si}: \mathrm{H}$ i-layer, and the formation of a $\sim 2 \mathrm{~nm}$-thick interface layer with a maximum $\mathrm{SiH}_{2}$ hydrogen content of 27 at.\% can be seen at the a-Si:H/c-Si interface. The large $\mathrm{SiH}_{2}$ content in the interface layer indicates poor network formation in this layer. From the SE result obtained simultaneously, we concluded that the formation of the $\mathrm{SiH}_{2}$ interface layer is induced by the island growth of the a-Si:H i-layer on the substrate [9]. As confirmed from Fig. 2 , the best solar cell efficiency coinsides with a thickness where the a-Si:H growth reaches a steady state after the interface layer formation.

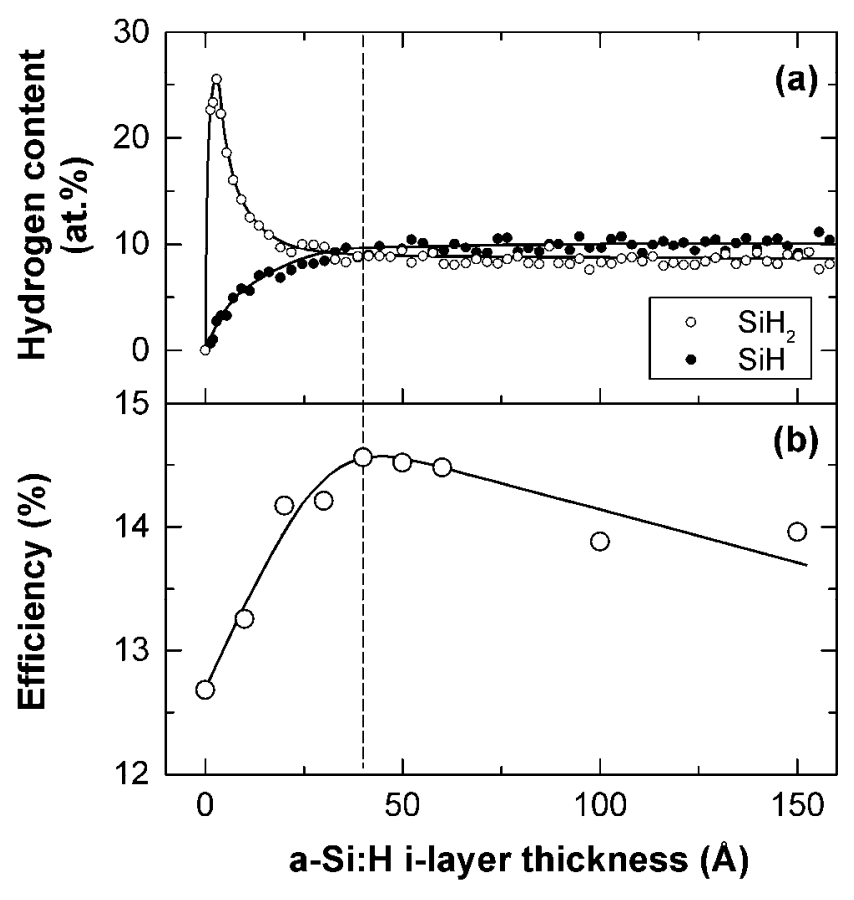

Fig. 2. (a) depth profiles of hydrogen contents and (b) solar cell efficiency, plotted as functions of the a-Si:H i-layer thickness [7].

In general, the creation of $\mathrm{SiH}_{2}$ bonds in amorphous network is accompanied by the generation of defects. Accordingly, the improvements in the solar cell characteristics up to 40 
$\AA$ are likely caused by reduction in defect density with increasing the i-layer thickness; in other words, solar cell characteristics degrades seriously when the defect-rich interface layer maintains extensive contact with the defective $p$-layer at the $\mathrm{p} / \mathrm{i}$ interface. The reduction in $\mathrm{J}_{\mathrm{sc}}$ observed at $0<\mathrm{i}$-layer $<4 \mathrm{~nm}$ could also be explained by the presence of the interface layer. When the i-layer thickness is increased further $(>4 \mathrm{~nm})$, on the other hand, the solar cell efficiency reduces due to the decrease in $\mathrm{J}_{\mathrm{sc}}[7]$.

So far, a number of studies have reported the improvement of a-Si:H/c-Si cell performance by the incorporation of a-Si:H i-layer at the a-Si:H/c-Si heterointerface $[2,11,12]$. This effect has been attributed to better properties of an a-Si:H(i)/c-Si interface, compared with an a-Si:H(doped)/c-Si interface $[2,11,12]$.

We have also found that the a-Si:H p-layer deposited directly on $\mathrm{H}$-terminated c-Si becomes partially epitaxial due to the presence of $\mathrm{H}_{2}$ gas during the growth and that the conversion efficiency of this solar cell shows a low value of $12.7 \%$. This is the case for the a$\mathrm{Si}: \mathrm{H}$ i-layer grown epitaxially on the crystalline substrate. The epitaxial interface formed at low temperatures is so defective as to deteriorate the interface quality.

Based on these results, we propose a passivation mechanism where the defective interface formed by the doped a-Si:H p-layer is spatially separated by the a-Si:H i-layer at a proper distance $(\sim 4 \mathrm{~nm})$, suggesting high quality of the passivation at a-Si:H i-layer and c-Si substrate interface even though the $\mathrm{Si}-\mathrm{H}_{2}$ rich layer is involved.

\section{$\underline{\text { Deposition temperature dependence }}$}

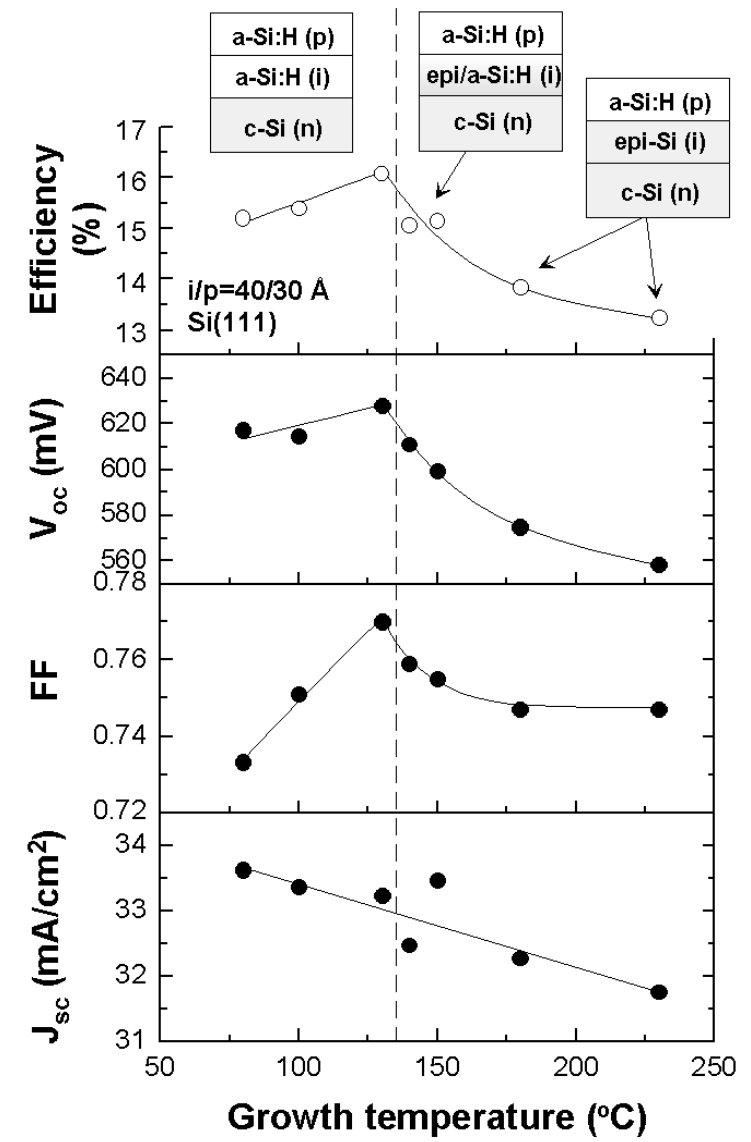

Fig. 3. Characteristics of the a-Si:H/c-Si heterojunction solar cell, plotted as a function of the growth temperature of the p-i layers. In the solar cells, the thicknesses were fixed to $i / p=4 / 3 \mathrm{~nm}$. The inset represents the phase structures of the p-i layers deduced from SE.

Figure 3 shows the solar cell performance, plotted as a function of the growth temperature $T_{G}$ of the $p-i$ layers. In this figure, the same temperature was used for the growth of the p-i layers. Accordingly, the result shown in Fig. 3 includes the temperature effects for both $\mathrm{p}$ and i-layers. The inset of Fig. 3 shows the phase structures of the p-i layers deduced 
from SE. One of our important finding is that the epitaxial growth of the i-layer occurs at $\mathrm{T}_{\mathrm{G}} \geq 140{ }^{\circ} \mathrm{C}$ even without the presence of $\mathrm{H}_{2}$ gas, as illustrated in the inset. In particular, the thickness of the p-i layers becomes zero when the epitaxial Si layer (epi-Si) is characterized by SE, since the complex refractive index of the epi-Si is essentially the same as that of the substrate. In other words, SE does not see the presence of the homoepitaxial layer optically. Thus, the epitaxial/ amorphous growth can be distinguished rather easily from the thickness or instantaneous growth rate during the $\mathrm{p}-\mathrm{i}$ layer growth using SE.

As shown in Fig. 3, the SE analysis revealed that the i-layer is partially epitaxial at $140 \leq \mathrm{T}_{\mathrm{G}}<180{ }^{\circ} \mathrm{C}$. At $\mathrm{T}_{\mathrm{G}} \geq 180{ }^{\circ} \mathrm{C}$, however, the i-layer becomes completely epitaxial, although the p-layer is still amorphous. It should be emphasized that transmission electron microscopy (TEM) also confirmed the heterointerface structures shown in Fig. 3 [14]. It can be seen that the epi-Si growth degrades the solar cell characteristics severely even when the thickness of epi-Si is quite thin $(\sim 2 \mathrm{~nm})$. In particular, the $\mathrm{V}_{\text {oc }}$ shows a low value of $\sim 560 \mathrm{mV}$ when there is no a-Si:H i-layer $\left(\mathrm{T}_{\mathrm{G}} \geq 180^{\circ} \mathrm{C}\right)$. Thus, the a-Si:H i-layer is quite important for obtaining high $\mathrm{V}_{\mathrm{oc}}$. At $\mathrm{T}_{\mathrm{G}} \leq 130{ }^{\circ} \mathrm{C}$, on the other hand, the $\mathrm{p}$-i layers are amorphous. At lower process temperatures, however, the efficiency reduces due to the decrease in FF. We attributed this to the low activation of the boron dopant in the a-Si:H p-layer owing to the low process temperatures. The result in Fig. 3 shows clearly that the optimum growth temperature for the a-Si:H/c-Si solar cells is just below the onset temperature of the Si epitaxial growth. Furthermore, the above results support the validity of real-time SE in characterizing the complicated structural evolution. The evaluation of such structures is of significant importance, since the epitaxial growth seriously degrades the solar cell performance [14].

\section{Annealing studies}

In the series of the annealing studies, we have adopted the lifetime measurements for evaluating the passivation quality. Figure 4 shows how the surface passivation quality of a single intrinsic $a-\mathrm{Si}: \mathrm{H}$ film of about $50 \mathrm{~nm}$ thin (present on both wafer surfaces), for different values of $T_{\text {depo, }}$, changes as a function of the annealing temperature, $T_{\text {ann. }}$. The substrates here are $3.0 \Omega . c m p$-type FZ wafers. For the films deposited at the lowest temperature $\left(T_{\text {depo }}=105\right.$ ${ }^{\circ} \mathrm{C}$ ), initially the passivation is poor, but improves to a remarkable extent by annealing. By increasing the deposition temperature, $T_{\text {depo }}$, up to $180^{\circ} \mathrm{C}$, the surface passivation quality of as-deposited films improves. Here, post annealing up to $260{ }^{\circ} \mathrm{C}$ increases the values for $\tau_{\text {eff }}$ further, well in excess of $1 \mathrm{~ms}$. This situation is different for films deposited at $205{ }^{\circ} \mathrm{C}$. Annealing does not give rise anymore now to an improvement. For even higher values of $T_{\text {depo, }}$, the figure shows that the passivation quality actually goes down dramatically.

Although the data in Fig. 4 was for still relatively thick (50nm) intrinsic $a$-Si:H films with variable values for $T_{\text {depo }}$, in Fig. 5 it is shown how the electronic passivation quality of much thinner (few nm) $i$-, $p^{+}$- and $i / p^{+}$- structures changes by low temperature $\left(\leq 260{ }^{\circ} \mathrm{C}\right)$ post-deposition annealing. Here, $T_{\text {depo }}$ was constant at $155^{\circ} \mathrm{C}$. The table in the inset gives the values of the layer thickness $d_{\text {bulk }}$ and surface roughness $d_{\text {rough }}$ for the respective layers, as extracted again from SE measurements. For the $i$-case, the applied low temperature annealing treatment is again seen to have a beneficial influence on the passivation. This is different however for the $p^{+}$-case: here, annealing rapidly leads to passivation degradation. The latter situation is seen to be only slightly improved when an intrinsic buffer layer (of similar thickness as in the $i$-case) has been inserted underneath the $p^{+}$-film (i/p $p^{+}$-case): Starting with values similar as for the $p^{+}$-case, initially the passivation quality benefits from annealing. Nevertheless, from about $T_{\mathrm{ann}}=220^{\circ} \mathrm{C}$ on also here degradation sets in. Such trends have in the past been found to be irrespective of the dopant-type of low resistivity wafers [15]. We will now argue that the degradation mechanisms as seen in these two figures are of fundamentally different nature. 
First we discuss the case of passivation by intrinsic $a$-Si:H films. From the slopes of the exponential fits in the shown Arrhenius plot in Fig. 4, an activation energy, $E_{\mathrm{A}}$, can be extracted. These values are given in figure $6(\mathrm{~b})$ as function of $T_{\text {depo }}$. The area showing

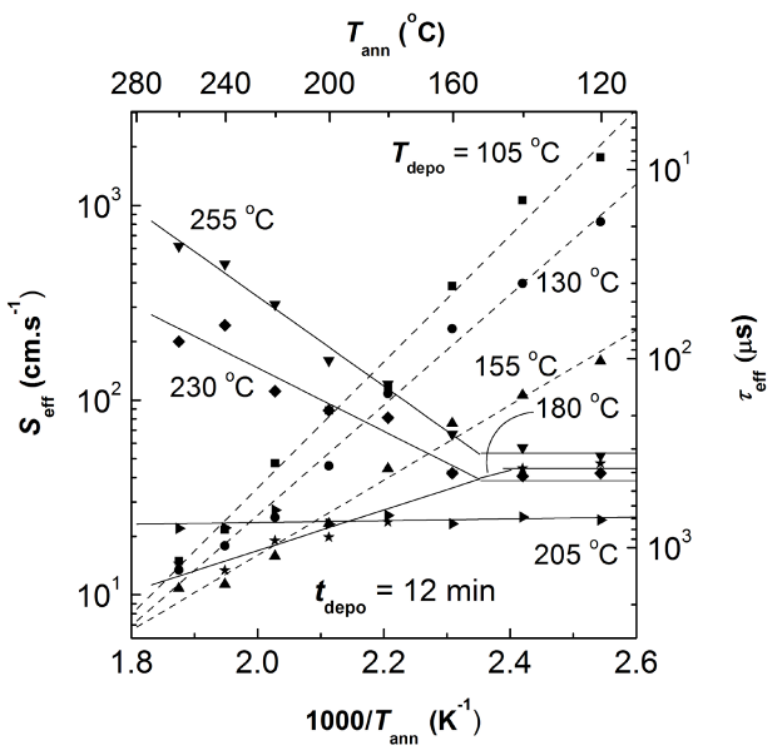

FIG. 4 Influence of $T_{\text {ann }}$ on the surface passivation quality for PECVD $a$-Si:H( $i$ ) films deposited on mirror polished (100) FZ-Si $(p)$ surfaces at different temperatures, $T_{\text {depo. }}$ All deposition times were $12 \mathrm{~min}$, whereas annealing times were $30 \mathrm{~min}$. Starting from the $T_{\mathrm{ann}}$ onset of annealing induced passivation changes, the shown lines are exponential fits of the data.

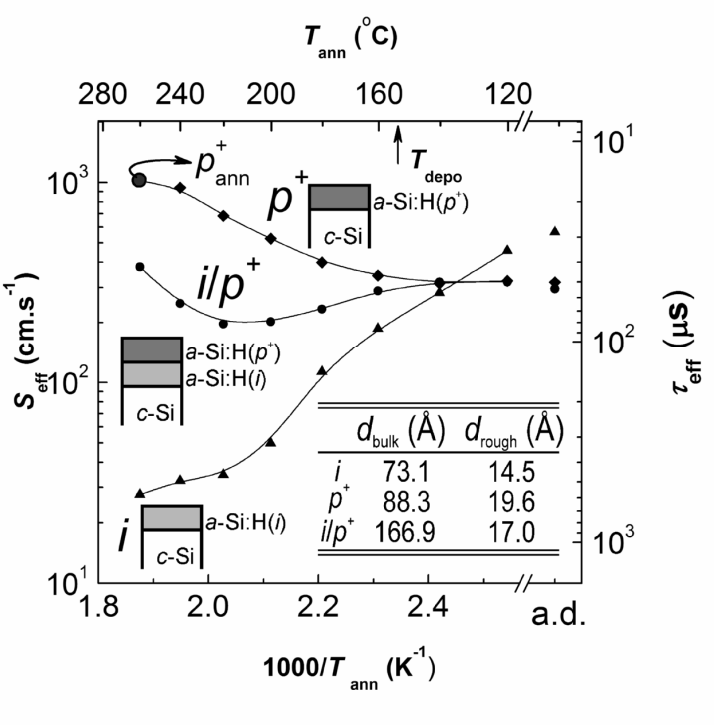

FIG. 5 Influence of $T_{\text {ann }}$ on the electronic passivation quality for thin intrinsic and doped $a$-Si:H layers deposited on mirror polished (100) FZ-Si $(n)$ surfaces. For reference, values for asdeposited films are given as well (label a.d. in the abscissa). The lines here are guides for the eye. The table in the inset gives the values of $d_{\text {bulk }}$, and $d_{\text {rough }}$ for the respective films, determined from SE measurements.

negative values for $E_{\mathrm{A}}$ corresponds to films for which post annealing is harmful for the passivation quality. This has been cross-hatched in the figure. Part (a) of the same figure gives the $a-\mathrm{Si}: \mathrm{H}(i)$ film thickness, $d_{\text {bulk, }}$, during the initial deposition stages, as function of $T_{\text {depo }}$. This data is obtained from fitting the measured SE data of the different samples to a two-layer model, taking the $50 \%$ void surface roughness on top of the $a$-Si:H film into account. For all films deposited at $T_{\text {depo }} \geq 205^{\circ} \mathrm{C}$, hardly any film growth can be observed with SE during at least the first $72 \mathrm{sec}$. The difficulty to fit the initial film thickness to the SE data suggests that for the complete surface the deposited material is crystalline [14]. This area is cross-hatched in the figure too: A good correspondence exists between the onset where crystalline material is grown at the full interface during film deposition, and the point where the value of $E_{\mathrm{A}}$ becomes negative[16].

The value for $E_{\mathrm{A}}$ is extracted from $\tau_{\text {eff }}$ measurements, hence its value will mainly be determined by the density of electronically active defects of the film. These are the defects that are within reach of the $c$-Si minority carrier wave function. The impact of these defects is determined by their energetic position within the bandgap and their electron and hole capture cross sections. This contrasts with, e.g., electron spin resonance (ESR) measurements of $a-\mathrm{Si}: \mathrm{H}(i)$ layers, which rather reveal paramagnetic defect densities in the bulk of relatively thick (typically a few $\mu \mathrm{m}$ ) films deposited on quartz substrates. Nevertheless, for $4 \mu \mathrm{m}$ thick films deposited at $25^{\circ} \mathrm{C}$, Biegelsen et al. observed in their ESR studies activation energies of about $0.5 \mathrm{eV}$ for the decrease of the $\mathrm{Si}$ dangling bond density by post deposition annealing at values for $T_{\text {ann }}$ up to $250{ }^{\circ} \mathrm{C}$ [17]. Considering the differences in measurement techniques, a 
good correspondence exists between this value for $E_{\mathrm{A}}$ and the ones obtained from $\tau_{\text {eff }}$ measurements for the films deposited at the lowest values $T_{\text {depo }}$ as presented in figure 6 .

For higher values of $T_{\mathrm{depo}}$, the value of $E_{\mathrm{A}}$ lowers and eventually passes through zero. Likely, this is because by increasing $T_{\text {depo }}$ the deposited material contains a lower dangling

(a)

(b)

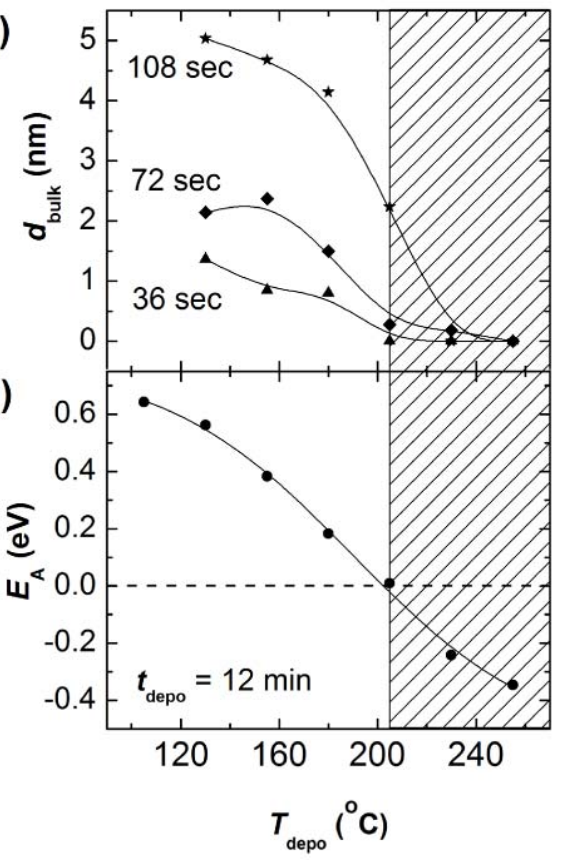

FIG. 6 (a) Calculated film-thickness, $d_{\text {bulk }}$, from $e x$-situ SE measurements as function of $T_{\text {depo, }}$ given for several deposition times, $t_{\text {depo }}$. Cross-hatched area shows films with epitaxially grown interface. (b) Extracted activation energy $E_{\mathrm{A}}$ as function of $T_{\text {depo }}$ for the films shown in figure 5 . Cross-hatched area shows films for which the surface passivation degrades by annealing. All films are intrinsic. The lines are guides for the eye.

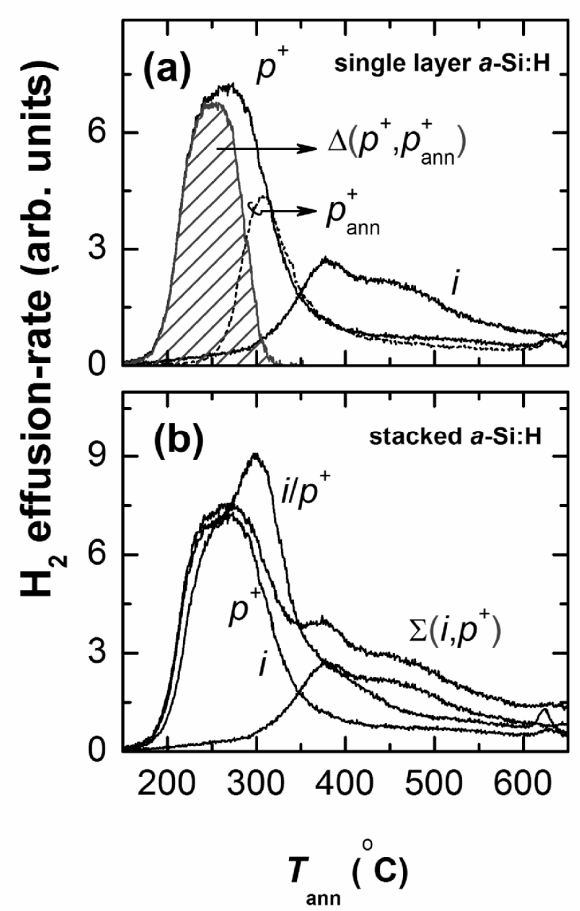

FIG. 7 Influence of $T_{\text {ann }}$ on $\mathrm{H}_{2}$ effusion rate of $a$-Si:H films as given in Fig. 1: (a) data for few nm thin single layer $a$ $\mathrm{Si}: \mathrm{H}$ films, as deposited and after the low-temperature annealing cycle described in Fig. 4 and 5. (b) data for asdeposited stacked doped films. Measurements by TDS.

bond density. When $E_{\mathrm{A}}$ equals to zero there is no net decrease in dangling bond density any more. For negative values of $E_{\mathrm{A}}$ annealing increases the dangling bond density. These results suggest that at all values for $T_{\text {depo }}$ two competing mechanisms may be at work during annealing, resulting in an increase and decrease of the dangling bond density, respectively. The net effect of these two mechanisms likely depends on how much hydrogen is available in the film for dangling bond passivation. This may explain why negative values of $E_{\mathrm{A}}$ correspond to epitaxially grown films, where it can be expected that the amount of available hydrogen is limited, and where it is known that such growth during $a-\mathrm{Si}: \mathrm{H}(i)$ deposition is detrimental for heterojunction device performance [18]. This result also shows that annealing combined with carrier lifetime measurements offers an alternative means, compared to transmission electron microscopy (TEM) or SE [19], to determine the abruptness of the interface.

To explain the experienced degradation in case of boron-doped films, first we show in figures 7 (a) and (b) TDS data of exactly the same structures as displayed in Fig. 5. Part (a) shows that for such thin films, the boron doping $\left(p^{+}\right.$-case) leads to $\mathrm{H}_{2}$ effusion at significant lower temperatures shown compared to intrinsic films, occurs. This phenomenon has been reported earlier in literature for thicker films [20]. The same figure also shows similar data 
(label $p_{a n n}^{+}$) for the doped film case after the stepwise annealing cycle, as described in Fig. 5. The crosshatched area in this figure (label $\Delta\left(p^{+}, p_{a n n}^{+}\right)$) represents the difference between these two signals and clearly demonstrates that during the latter cycle already significant $\mathrm{H}_{2}$ effusion takes place. Figure 7(b) compares $\mathrm{H}_{2}$ effusion rate data of the $i / p^{+}$-structure with that of the summed $i$ - and $p^{+}$-case (label $\Sigma\left(i, p^{+}\right)$). It is seen that at low temperatures more hydrogen effuses out for the $i / p^{+}$-case than for the combined $i$ - and $p^{+}$-cases. Note that the combined $i$ - and $p^{+}$-layer thickness practically equals that of the stacked $i / p^{+}$structure (see inset in Fig. 5).

For intrinsic $a$-Si:H material annealed at higher temperatures $\left(>300{ }^{\circ} \mathrm{C}\right)$, a correspondence between the $\mathrm{H}_{2}$ effusion rate and defect-generation in the film has been demonstrated in the past by comparing TDS, IR absorption and electron spin resonance measurements [ ] Consequently, for boron-doped $a-\mathrm{Si}: \mathrm{H}\left(p^{+}\right)$material, the effusion data suggests that hydrogen likely is already transferred at much lower temperatures from a $\mathrm{Si}-\mathrm{H}$ to a $\mathrm{H}_{2}$ state, creating defects in the material. The $\mathrm{Si}-\mathrm{H}$ bond rupture energy has been argued to depend on the Fermi energy (rather than on the actual dopants) in such material [21,22] . As discussed, in the present case, annealing rapidly results in electronic passivation losses for the $p^{+}$-case. Also here, the origin of this phenomenon likely is Fermi-level dependent defectgeneration, occurring close to the $a-\mathrm{Si}: \mathrm{H} / c-\mathrm{Si}$ interface.

For the $i / p^{+}$-structure, the initial improvement by annealing in passivation is again most probably due to out-annealing of defects in the intrinsic layer. At higher values for $T_{\mathrm{ann}}$, the passivation degradation of this stacked structure may be caused by two related phenomena: Firstly, dangling bonds are created already at low temperatures by annealing in the doped layer. As a consequence, the wavefunction associated with the minority carriers close to the interface in the $c$-Si material may probe through the intrinsic film, when sufficiently thin, to collapse in the defect rich doped overlayer [23]. Secondly, in addition to this, due to the presence of the $p^{+}$-layer on top of the $i$-layer, also in the latter layer the Fermi-level will be shifted towards the valence band of the material. As a result, also here already at moderate annealing temperatures, $\mathrm{Si}-\mathrm{H}$ bond-rupture can be expected to take place in the buffer layer too [24]. This is evidenced in Fig. 7 (b), where it can be seen that at lower temperatures more $\mathrm{H}_{2}$ effuses out of the stack than for the two films measured separately. Conversely, at higher temperatures a smaller amount effuses out. Consequently, it must be concluded that the presence of a $p^{+}$-type overlayer likely enhances $\mathrm{Si}-\mathrm{H}$ bond rupture in the intrinsic buffer layer. As a result, also for the $c-\mathrm{Si} / a-\mathrm{Si}: \mathrm{H}(i) / a-\mathrm{Si}: \mathrm{H}\left(p^{+}\right)$structure, high dangling bond densities may be generated not only in the doped over layer, but also close to the $c$-Si / $a$-Si:H interface, already at relatively low values for $T_{\text {ann }}$.

\section{Application of a-SiO:H p-i layers}

Thus, a-Si:H has been employed for the passivation of c-Si, whereas it is still an open question that a-Si:H is the best material for heterojunction. A disadvantage of a-Si:H is the absorption of short wavelength light and the partially epitaxial growth on the c-Si substrate. In order to overcome these problems, we have developed a-SiO:H/c-Si heterojunction structures. For the deposition of the a-SiO:H p-i layers, a rather high growth temperature of $180{ }^{\circ} \mathrm{C}$ was used to improve the film quality [25]. Figure 8 shows the variation of the solar cell performance with $\mathrm{CO}_{2}$ flow rate in the a-SiO:H i layer. In Fig. 8, the oxygen contents in the a-SiO:H i layers were estimated to be 4 at.\% $\left(\left[\mathrm{CO}_{2}\right]=1 \mathrm{SCCM}\right)$ and 7 at.\% $\left(\left[\mathrm{CO}_{2}\right]=2\right.$ $\mathrm{SCCM})$. For the deposition of the a-SiO:H p layer, $\left[\mathrm{CO}_{2}\right]=2 \mathrm{SCCM}$ was also used.

At $\left[\mathrm{CO}_{2}\right]=0 \mathrm{SCCM}$, formation of the epi-Si layer occurs, since the growth temperature is $180{ }^{\circ} \mathrm{C}$ in Fig. 4. Quite interestingly, we find that a small flow rate of $\left[\mathrm{CO}_{2}\right]=0.5$ SCCM $\left(\left[\mathrm{CO}_{2}\right] /\left[\mathrm{SiH}_{4}\right]=10 \%\right)$ is sufficient to suppress the $\mathrm{Si}$ epitaxial growth completely. As shown in 
Fig. 8, we obtained the best efficiency of $16.0 \%$ when the oxygen content in the a-SiO:H i layer is 4 at.\% $\left(\left[\mathrm{CO}_{2}\right]=1 \mathrm{SCCM}\right)$. This efficiency can be compared with $15.8 \%$ obtained from the optimized a-Si:H p-i layers. The greatest advantage of the a-SiO:H p-i layers, however, is suppression of the epi-Si growth on c-Si substrates by the a-SiO:H i layer. In particular, the a$\mathrm{SiO}: \mathrm{H}$ i layer enables us to change the deposition conditions freely without forming epi-Si layers. The application of the a-SiO: $\mathrm{H}$ i layer further improves the reproducibility for solar cell fabrication, since the optimum deposition conditions of a-Si:H i layers lie near a-Si:H/epiSi phase boundaries [14]. Thus, by applying a-SiO:H p-i layers, high-efficiency solar cells can be fabricated more easily, compared with conventional a-Si:H/c-Si solar cells.

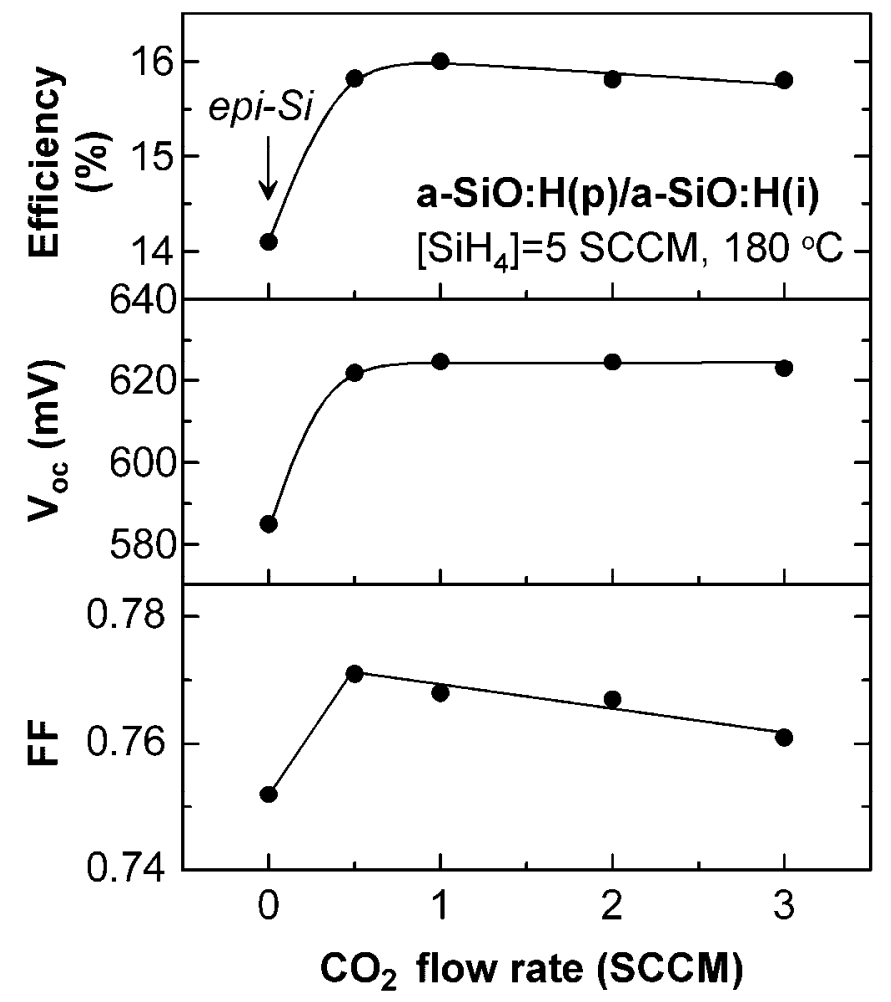

Fig. 8 Variation of the solar cell performance with $\mathrm{CO}_{2}$ flow rate in the a-SiO:H i layer [25].

\section{SUMMARY}

In summary, we discussed how interface properties of $a-\mathrm{Si}: \mathrm{H} / c-\mathrm{Si}$ structures may determine the electronic passivation behavior in conjunction with the solar cell performance. The beneficial combination of a-Si:H( $p, n)$ and a-Si:H(i) for passivation is explained in terms of the defective interface with a doped layer and the excellent interface with an intrinsic layer. Post annealing treatments have been found to be a good tool to unravel the physical mechanism of passivation. The annealing studies demonstrate the need for a careful assessment of process temperature during $c-\mathrm{Si} / a-\mathrm{Si}: \mathrm{H}$ heterostructure device fabrication. For intrinsic film deposition, the deposition temperature should be sufficiently low to prevent epiSi growth. For doped layer deposition, care has to be taken not to generate harmful defects already at moderate temperatures. The novel material a-SiO:H demonstrates the advantage of the prevention of harmful epitaxial growth and less optical absorption. 


\section{Acknowledgements}

The authors would like to thank Drs. M. Tanaka, M. Taguchi and A. Terakawa (Sanyo Electric) for their fruitful discussion. This work is partly supported by NEDO.

\section{REFERENCES}

[1] H. Matsuura, T. Okuno, H. Okushi, and K. Tanaka, J. Appl. Phys. 55, 1012 (1984).

[2] M. Tanaka, M. Taguchi, T. Matsuyama, T. Sawada, S. Tsuda, S. Nakano, H. Hanafusa, and Y. Kuwano, Jpn. J. Appl. Phys. 31, 3518 (1992).

[3] E. Yablonovitch, T. Gmitter, R.M. Swanson, and Y.H. Kwark, Appl. Phys. Lett. 47, 1211 (1985).

[4] M. Taguchi, A. Terakawa, E. Maruyama, and M. Tanaka, Prog. Photovolt: Res. Appl. 13, 481 (2005).

[5]S. De Wolf, G. Agostinelli, G. Beaucarne, and P. Vitanov, J. Appl. Phys. 97, 063303 (2005).

[6] H. Fujiwara, M. Kondo, and A. Matsuda, J. Appl. Phys. 91 (2002) 4181.

[7] H. Fujiwara and M. Kondo, J. Appl. Phys. 101 (2007) 054516.

[8] H. Fujiwara, J. Koh, P. I. Rovira, and R. W. Collins, Phys. Rev. B 61 (2000) 10832.

[9] H. Fujiwara, J. Koh, P. I. Rovira, and R. W. Collins, Phys. Rev. B 61 (2000) 10832.

[10] R.A. Sinton and A. Cuevas, Appl. Phys. Lett. 69, 2510 (1996).

[11] M. Taguchi, K. Kawamoto, S. Tsuge, T. Baba, H. Sakata, M. Morizane, K. Uchihashi, N. Nakamura, S. Kiyama, and O. Oota, Prog. Photovolt: Res. Appl. 8 (2000) 503.

[12] M. W. M. van Cleef, J. K. Rath, F. A. Rubinelli, C. H. M. van der Werf, R. E. I. Schropp, and W. F. van der Weg, J. Appl. Phys. 82 (1997) 6089.

[14] H. Fujiwara and M. Kondo, Appl. Phys. Lett. 90 (2007) 013503.

[15] S. De Wolf and M. Kondo, in Proceedings of the 4th World Conference on Photovoltaic Energy Conversion, Waikoloa, Hawaii (IEEE, Piscataway, NJ, 2006), p. 1469.

[16] S. De Wolf and M. Kondo, Appl. Phys. Lett. 90, 042111 (2007).

[17] D.K. Biegelsen, R.A. Street, C.C. Tsai, and J.C. Knights, Phys. Rev. B 20, 4839 (1979).

[18] T.H. Wang, E. Iwaniczko, M.R. Page, D.H. Levi, Y. Yan, H.M. Branz, and Q. Wang, Thin Solid Films 501, 284 (2006).

[19] D.H. Levi, C.W. Teplin, E. Iwaniczko, Y. Yan, T.H. Wang, and H.M. Branz, J. Vac. Sci. Technol. A 24, 1676 (2006).

[20] W. Beyer, H. Wagner, and H. Mell, Solid State Comm. 39, 375 (1981).

[21] R.A. Street, C.C. Tsai, J. Kakalios, and W.B. Jackson, Philos. Mag. B 56, 305 (1987).

[22] W. Beyer, Physica B 170, 105 (1991).

[23] S. De Wolf and G. Beaucarne, Appl. Phys. Lett. 88, 022104 (2006).

[24] S. De Wolf and M. Kondo, Appl. Phys. Lett. 91, 112109 (2007).

[25] H. Fujiwara, T. Kaneko and M. Kondo, Appl. Phys. Lett. 91 (2007) 133508. 